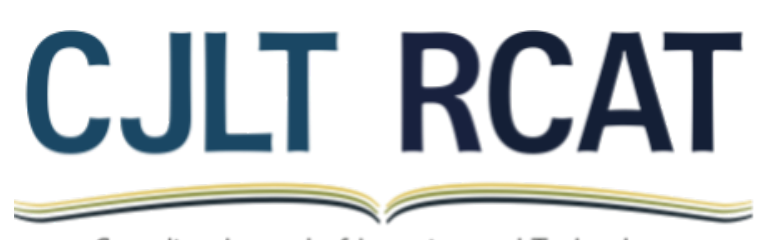

Canadian Journal of Learning and Technology

La Revue canadienne de l'apprentissage et de la technologie

Volume 47 (4)

Special Issue 2021

\title{
Pedagogical Transformation and Teacher Learning for Knowledge Building: Turning COVID-19 Challenges into Opportunities
}

\section{Transformation pédagogique et formation d'enseignant·e.s en coélaboration de connaissances : convertir des obstacles en opportunités au temps de la Covid-19}

\author{
Chew Lee, Teo, National Institute of Education, Singapore \\ Seng Chee, Tan, National Institute of Education, Singapore \\ Carol Chan, Hong Kong University, China
}

\begin{abstract}
This paper reports on a Knowledge-Building Community (KBC) continual effort connecting teachers within and across schools for knowledge creation and community building during the COVID19 disruptions. During this crisis, schools around the world are being challenged with the issues of implementing online learning. We identified three areas of misalignments: disjoint in learning with home-school separation, piecemeal technologies to mimic physical teaching, and disconnect between teacher professional development and classroom practices, and we discussed emerging realignment efforts for transformative learning. Through analyzing the three cases of how teachers responded to COVID-19 challenges in inter-related areas of curriculum, pedagogy, technology, and community, several themes on emerging alignments conducive for transformative pedagogy and technology through community advancement were identified. These themes include innovating practice around the centrality of ideas, perceiving knowledge building as pervasive, transformative use of technology, and symmetrical advancement of knowledge where expertise is distributed within and between communities. These case examples show that in these disruptive times, the teachers were more actively building new practices supported by the community dynamics and systemic processes of the KBC. Consequently, the interactions between stakeholders shifted from disjointed relations in different hierarchical levels to a network community of people, ideas, and resources, and teachers continually advancing their knowledge-building practice in these challenging times.
\end{abstract}

Keywords: Knowledge-building community; Discourse; Teacher professional development; Knowledge building classroom 


\section{Résumé}

Cet article rend compte de l'effort continu d'une communauté d'élaboration de connaissances (CoÉco) pour connecter les enseignant·e·s d'une même école et d'écoles différentes à des fins de création ou de coélaboration de connaissances pendant les perturbations de la COVID-19. Depuis le début de cette crise, les écoles du monde entier ont été confrontées aux problèmes de mise en œuvre de l'apprentissage en ligne. Nous avons d'abord identifié trois zones de désalignement : la disjonction de l'apprentissage de par les réalités maison-école distinctes, l'usage fragmenté de technologies pour imiter l'enseignement en salle de classe et la déconnexion du développement professionnel des enseignant·e's des pratiques de classe. Par la suite, nous avons discuté de réalignements émergents pour un apprentissage transformateur. En analysant trois cas où des enseignant·e·s ont relevé des défis reliés à la COVID-19 dans les aires interdépendantes que sont le programme d'études, la pédagogie, la technologie et la communauté, nous avons repéré plusieurs thèmes rattachés à des alignements émergents propices à une pédagogie et une technologie transformatrices de par l'avancement de la communauté. Ces thèmes comprennent une pratique innovante qui repose sur la centralité des idées, la perception de la coélaboration de connaissances comme omniprésente, l'utilisation transformatrice de la technologie et l'avancement symétrique des connaissances là où l'expertise est distribuée au sein des communautés et entre celles-ci. Ces cas exemplaires montrent qu'en ces temps perturbés, les enseignant·e·s ont été plus actifs à développer de nouvelles pratiques soutenues par la dynamique communautaire et les processus systémiques de la CoÉco. Par conséquent, les interactions entre les partenaires sont passées de disjointes, observées à différents niveaux hiérarchiques, à des interactions de personnes, d'idées et de ressources au sein de la communauté en réseau alors que les enseignant·e·s faisaient progresser leur pratique de coélaboration de connaissances en ces temps difficiles.

Mots-clés : Communauté d'élaboration de connaissances ; discours ; développement professionnel des enseignants ; classe de coélaboration de connaissances

\section{Introduction}

At the peak of COVID-19, according to UNESCO (2020), affected schools were reported in about 194 countries, which accounted for more than $90 \%$ of learners worldwide. In Singapore, where this case study was conducted, circuit breaker (lockdown) measures were imposed on the general population from April - June 2020. Preschools and primary and secondary schools went into homebased learning immediately. While optimists suggest that the COVID-19 situation propelled the adoption of online learning, the "panicked" change also invited criticisms of the quality of online teaching and learning and the level of student engagement. This disruption warrants our attention as we brace for current and future disruptions and new norms. 
This paper focuses on a knowledge-building community $(\mathrm{KBC})$ and its members' efforts to engage students in knowledge building ${ }^{1}$ (KB) while dealing with COVID-19 challenges. KB practice aims to inculcate authentic and creative knowledge work into classrooms of all ages. Teachers respond to students' inquiry need and nurture their idea growth by supporting them to dig deeper, elaborate on their ideas, and consider new or potential problem areas (Bereiter \& Scardamalia, 2014). The paper narrates three levels of teacher KBC: (i) an individual teacher connected to the cross-school community, (ii) a school-based community, and (iii) a cross-school community. We examine the realignment of teachers' practices in the cross-school community as they explored KB pedagogy in their individual classrooms throughout the lockdown. The first two case studies, an individual teacher and a school-based teacher KBC, describe the teachers' knowledge building efforts with their students in class while they engage with a larger teachers' KBC. This paper ends with a third case study detailing the teachers in the cross-school KBC. We discuss how the community building dynamics, using asynchronous and synchronous platforms and students' ideas, motivated the teachers to continually innovate during the disruption. Teachers viewed anomalies as part-and-parcel of their daily work. Such a KBC cultivated a sense of belonging and creativity within the community that spurred the members to embrace the new context.

\section{Examining the Misalignments}

During the COVID-19 lockdown students learned from home using technologies, and teachers were forced to switch their mode of teaching. How can this become an opportunity to transform practice and prepare teachers and students for the new normal after the COVID-19 pandemic? Rather than treating disruption as a negative and reactive response to some external factors, teaching and learning practice can be viewed as inherently disruptive - the sort of positive disruption that comes from the unpredictability of students' questions, curiosity, and novel ideas. In this regard, KB practice presents itself as a system of theories, pedagogy, and technology that informs classroom practice; one that requires teachers to continually make sense of emerging students' thoughts and ideas (Yang et al., 2020; Tan et al., 2021). In uncovering the dynamics of KB classrooms, we gain insight into how disruption unveils the misalignments in classroom practices and how such disruption can provide opportunities for the teacher KBC to make collective advancement. We first outline three misalignments.

\section{Disjoint in Learning, Both Within and Across a Subject, as well as Between Learning Inside and Outside of Classrooms}

Disjoint in learning can manifest in many ways and is being exacerbated during the COVID-19 pandemic: students' learning can be affected if the ideas and subject topics are sequenced and presented as unrelated units. Within a school, compartmentalization of subjects can create the misconception that knowledge learned under different subjects are independent of one another. While many teachers acknowledge that learning can happen in and out of classrooms, they still consider institutionalized

\footnotetext{
${ }^{1}$ For further detail on Knowledge Building Theory and more in-depth explanation of the Knowledge Building Principles, we recommend the following article: (Scardamalia, 2002).
} 
teaching and learning essential in a child's learning experience. The "other" learning activities either complement what the child is learning in a classroom or are a good-to-have. Such disjoints have led to limited attempts to deal with COVID-19 challenges, such as making home-based learning (HBL) similar to institutionalized classroom learning. There have been myriad efforts to pursue alignment within the school system, the curriculum, the pedagogy and assessments (Hayes et al., 2020); the COVID-19 situation is providing the catalytic force. We argue that addressing this misalignment is to retune the perceptions of content, syllabus, and learning boundary. It should be recognized that the nature of learning is seamless and pervasive, and in fact, new ways of rich learning are happening outside the classrooms, from which the classroom needs to take a cue.

\section{Using Technologies to Imitate In-Person Teaching}

The centrist view of learning in and out of the classroom affects learning designed for online and offline engagement. Instead of leveraging the affordances of technologies to transform teaching and learning within an integrated environment, there is a tendency to mimic face-to-face mode in the online mode. During the lockdown period we read of teachers setting up multiple computers in their Zoom lessons to replicate classroom interaction - one screen to capture students' responses, another to display the teacher's writing on the online "whiteboard", and another to see the students' faces to replicate an in-class setting. (This example is taken from a Facebook post from a closed teachers' community in Singapore that explores technology integration in teaching and learning.) The effort and commitment to reach out to students is admirable but may not be a meaningful use of technology. In mimicking the classroom's usual practice, not only are new interactions afforded by technology not leveraged, but the misalignment may have inadvertently widened. The less skillful and less resourced teachers would consider such online teaching and learning daunting; for the savvy teachers, the creativity is channeled into replicating classroom interaction instead of transforming learning. This paper attempts to study a sustained transformative view of technology for teaching and learning, coupled with teachers' experiences of the technology in their professional development (PD).

\section{Disconnect Between Professional Development and Practices}

The disconnect between teachers' professional development and practices has been discussed in the literature (Larson \& Archambault, 2019; Ebert-May et al., 2011; Nahal, 2010). The number of online support groups and online resources built for teachers flourished during the COVID-19 pandemic (Ferdig et al., 2020). The appearance of these support communities on the Internet is encouraging and provides just-in-time support and resources for teachers. Beyond providing resources, tips and strategies, how can online communities provide effective and sustainable support to teachers to change their practice beyond the COVID-19 crisis? The case studies that follow revolve around creating a technology-enhanced professional experience for teachers, supported by the teacher KBC. The discussions and activities were designed for the KBC teachers as examples for classroom engagement with students. Such symmetry between teachers' preparation and practice can serve as a sustainable mechanism to tackle ongoing disruptions. 


\section{Knowledge-Building and Knowledge-Building-Community}

In recent years, community-based professional development (Bolam et al., 2005; Laferrière, 2018) and professional learning communities (DuFour et al., 2016; McLaughlin \& Talbert, 2006) have become major research themes. However, a review of systems revealed that progressive approaches to community-based professional practices that sustain continual improvement and innovative work remain few and far between (Toh et al., 2014). This paper draws from the research tradition of KB (Chan et al., 2019; EDUsummIT Thematic Work Group 13, 2019) developed by Scardamalia and Bereiter (2010) since the 1990s. The KB practice is built on the premise that students are capable of real, creative work with ideas. Students in the KB classroom engage in discourse to improve ideas and deepen knowledge via Knowledge Forum (KF), an online discourse platform that supports the process of creative work with ideas. In KF, students post questions, ideas, and information in a shared space. Students can also build on, annotate, and co-author notes. Figure 1 shows the KF interfaces and features that support such collective inquiry and collaborative discourse among teachers and students.

$\mathrm{KBC}$ differs from many practice-oriented communities as it enculturates teachers into a highly innovative culture (Scardamalia \& Bereiter, 2010) that values the emergence and development of ideas. Distinctive from other inquiry-based models using technology, KBC focuses on creative knowledge work (Chan \& Van Aalst, 2008; Chan \& Yang, 2018) and teachers creating knowledge of practices. Teachers are the point of contact between multiple layers of networks (Toh et al., 2014). They connect their professional learning with their innovative practice improvement. This paper uses different knowledge building principles to examine pedagogical transformation and teacher learning. For example, the principles of real ideas and authentic problems can be used to analyse the way teachers shape the inquiry problem in class if the teacher values that the questions and problems came from students' genuine effort to understand the world, or if they value how much the inquiry covers the stipulated curriculum. This study reports on three cases of teacher practice and professional growth during the pandemic addressing the misalignments and illustrating the dynamics and enabling conditions of the KB teacher community.

\section{Research Context and Focus}

\section{Context and Participants}

The participants were part of a three-year study on a KBC teacher network focusing on the development of teachers' leadership and knowledge in community-based professional development. Members of the KBC, supported by an educational institution in Singapore, have met quarterly since 2016, and they continued their KB practice during COVID-19 lockdown. The three case studies (all related to the cross-school $\mathrm{KBC}$ ) include:

(1) A secondary school teacher in the KBC teacher network;

(2) Six teachers from a pre-school community in the KBC teacher network; and

(3) Cross-school communication and two online sessions attended by 18 and 24 preschool, primary and secondary teachers respectively, from the $\mathrm{KBC}$ teacher network. 


\section{Figure 1}

Features of KF Supporting Design, Elaboration, and Improvement of Teachers' Ideas

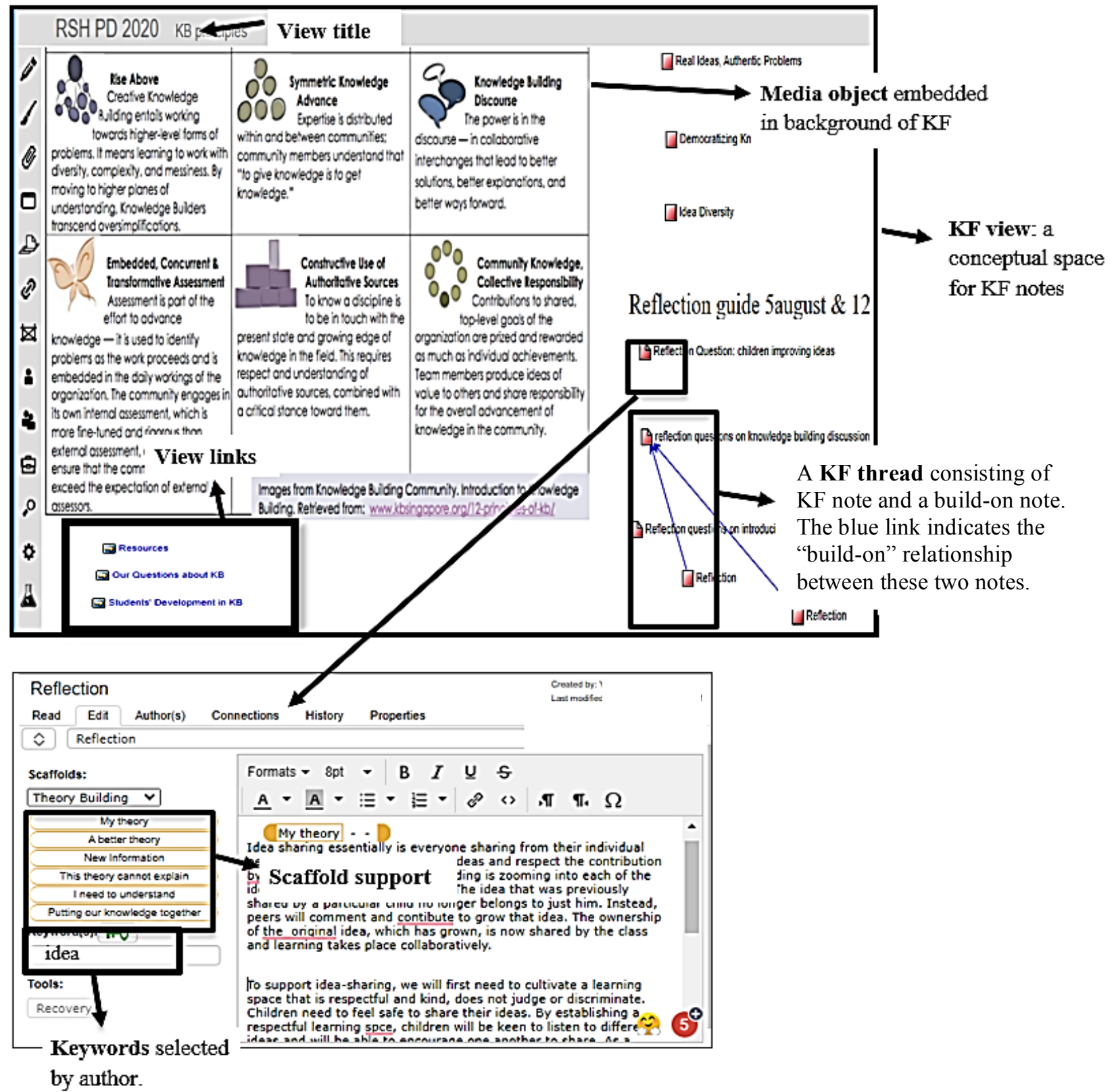

\section{Research Focus}

A case study approach was employed to surface the context-dependent knowledge drawn together from the voices, actions, interactions, and ideas in these connected cases of teachers and teachers' communities. The research question explored was: How did the KB teachers transform pedagogy and technology scaffolding of students in $\mathrm{KB}$, and how did they advance their knowledge and skills, supported by the KBC, for professional growth during COVID-19 lockdown? 
Data were collected over two months when teaching and learning activities were impacted by COVID-19. The data included (a) reflective and discussion notes of teachers and students on KF; (b) knowledge and learning artifacts; (c) interview data; and (d) teacher discourse during KBC meetings. The data were examined for teachers' rationale, approach, and reflection about KB practice during COVID-19. Qualitative analyses identified critical events and key themes, guided by the conceptual lens of emerging alignments for transformative pedagogy and teacher learning in KBC. Specific focuses included (i) how the teachers leveraged pedagogy and technology at the different levels of network; and (ii) how knowledge of practice was distributed and built as teachers interacted as a community in the KBC.

\section{Case Study 1. An Individual Teacher in the KBC}

We first analyze the work of Teacher Jane's KB endeavor in a secondary school during the lockdown, paying special attention to Jane's practice and her interactions with the teacher KBC. In March 2020, COVID-19 became serious and schools were compelled to institute HBL. Jane moved away from $\mathrm{KB}$ initially but readily returned to develop innovative practices despite the disruption. Jane called the KB pedagogy "the thinking pedagogy." While Jane was the only teacher working on KB in her new school, she was connected with the cross-school KBC through network meetings (see Case Study 3). Several themes emerge in the analysis of Jane's KB practice and professional growth supported by the network.

\section{Realigning Curriculum: Real-world Problem for HBL Setting}

Jane has been part of a teacher KBC that supported her to sustain innovative pedagogy during the crisis. During a time when many were busy responding to the administrative and technical demands of HBL, Jane was challenging the boundaries of practice in new ways with a heightened focus on students' agency and experience. She reflected that HBL provided a natural opportunity to challenge all previous practices.

At a network meeting, Jane shared her motivation to return to KF during the HBL. As she entered the second month of HBL, she contemplated ways to approach her students on the topic of photosynthesis. She recognized the "disjoint in learning" and noted how her students were "bombarded" with video after video in HBL. She knew that was not the way to do it. She understood the importance of curriculum alignment and recalled her experience with the "vertical farming" activities in the students' KB design studio the year before; an event that involved students and teachers working together to build knowledge about real-world problems such as "sustainability living." Jane took the opportunity to use the challenge of vertical farming to start the KF discussion on photosynthesis. She redesigned the fixed curriculum on photosynthesis to reflect a more open curriculum that mapped to authentic learning in a HBL setting. Instead of going through the facts and definition of photosynthesis and discussing assessment questions, Jane got her students to explore the authentic farming problem on KF. Engaging them in a novel problem and trusting that they would gain a deeper understanding of photosynthesis and plants in general, Jane's starting point was curriculum realignment. 


\section{Realigning the Role of Technology to Transform Learning During HBL}

Instead of watching videos during HBL, Jane made use of KF transforming pedagogy and developing student collective agency. Jane talked about how she navigated between KF views and how she encouraged her students to use and evaluate source materials to refine their ideas. The pandemic and HBL opened more possibilities. Supported by technology, Jane sought ways to flip the responsibility of leading the KB discussion to the students. Throughout her sharing, she reiterated how KB broadened her horizons on how lessons could be conducted.

Four clusters of ideas grew on KF: "artificial light," "light spectrum," and "space" emerged from the topic of "light as a way to make plants grow better in vertical farming." These ideas led students to question the roles of modernization and the environmental approach to agriculture. Students probed the issues of vertical farming, as seen from the novel questions (Figure 2a). Jane also brought in a vertical farming expert to join the students at a student-led conference in Zoom (Figure 2b). The use of different forms of technology enabled students to pursue inquiry and deep learning from experts despite the lockdown, and widened their perspectives.

\section{Teacher Learning and Support from Cross-School KBC}

Jane's professional growth was supported by the cross-school KBC at different phases. She made symmetrical advances in her understanding and practice of $\mathrm{KB}$ along with novice and expert $\mathrm{KB}$ teachers within and between the communities. Symmetric knowledge advancement is a KB principle whereby Scardamalia (2002) suggests that expertise is distributed among members in a community and all benefit through the exchange of ideas. Jane shared that the use of KF in HBL was quite different from integrating KF in a physical classroom. She shared her technical questions at a network meeting and discovered the new features, the "promising idea tool" and "hierarchical view" on KF. She used the tools progressively to identify the ideas, moved them to the second KF view for further discussion, and introduced the tool to the students to identify ideas and questions worth pursuing. Over time, Jane developed confidence in the technology with just-in-time training on the promising idea tools and hierarchical KF views. While she was the only teacher in her school working on KB, she benefited from COVID-19 by connecting with the KBC teacher network. She also played an important role in sharing her KB lessons with other teachers at two cross-school KBC meetings in April and May 2020 (see more discussion in Case 3).

Jane developed more facilities for HBL using KB. Sharing her lessons at two cross-school KBC meetings in April and May 2020, Jane articulated how students could go beyond a superficial understanding of "what is photosynthesis?" to exploring photosynthesis in the farming system. She reflected, "Because of HBL, I now truly understand the value of KF." The disruption and challenge of HBL helped Jane engage more deeply and the opportunity to share at the KBC meetings also helped her develop professionally. 


\section{Figure 2a}

Knowledge Forum Views and Students Conference - Emerging KF Views Capturing Deepening Conversation
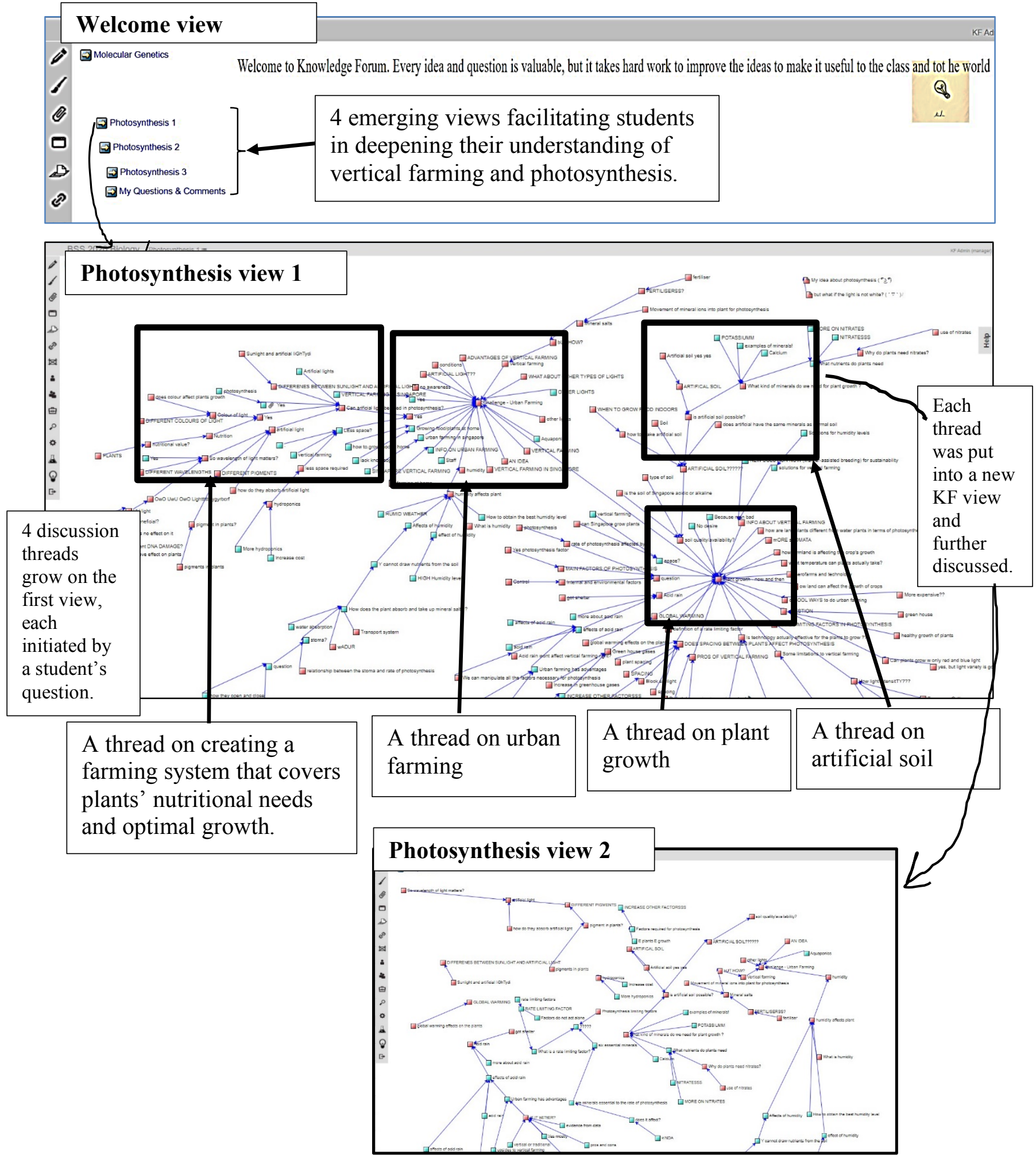

Pedagogical Transformation and Teacher Learning for Knowledge Building: 


\section{Figure 2b}

Knowledge Forum Views and Students' Conference - Student-led E-conference Based on the KF Discussion on Vertical Farming

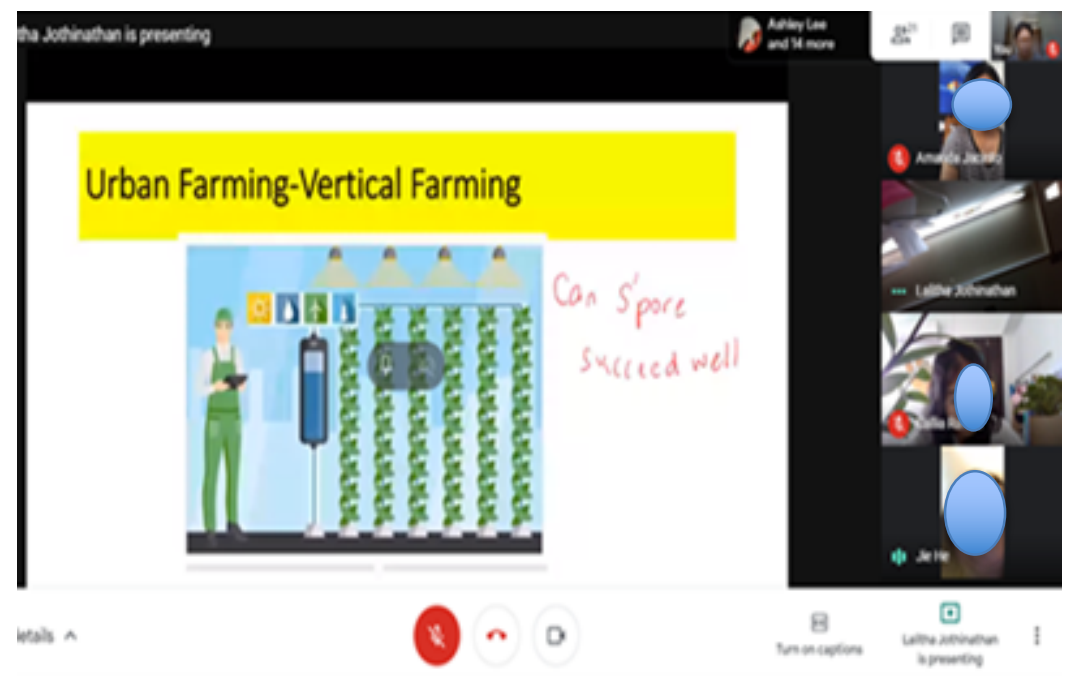

\section{Case Study 2: A School-Based Teacher Community within the KBC}

This study involves six preschool teachers who had less than one year of KB experience. Weekly one-hour school-based discussions were held as part of an ongoing PD program. Despite the changes brought on by COVID-19, the teachers persisted in their weekly meetings and started on two topics via KF and Zoom meetings: "The Amazing Human Body" for the five-year-olds and "Science in Everyday Life" for the four-year-olds. The KF notes became the subject of discussion at each synchronous Zoom meeting. Figures $3 \mathrm{a}$ and $\mathrm{b}$ show screenshots of the teachers' KF view that reflect a mixture of lesson ideas and resources. The KF view background is a graphic that represents the possible topics in the "amazing human body" and the connections.

\section{Realigning Curriculum: Calibrating Syllabus to KB Pedagogy}

Somewhat similar to Jane's redesigning of the curriculum, the teachers' first collective thought was to create a new syllabus: a "KB syllabus" that foregrounds meaningful issues anchored in the context of their children's everyday activities. This preschool teacher community decided to do away with prescribed activities defined in the previous syllabus. The first move was to revolve their planning and lesson activity ideas around the visual of a connected syllabus embedded into a KF view, the KF database in their school (Figure 3a). This connected syllabus visual has a prominent central idea of "our amazing human body system" which maps the different systems in our body along with the interconnectedness of individual systems to one another. Teachers used the visual to organize their ideas as KF notes.

As each discussion progressed, the teachers put up their KF notes describing possible lesson activities, and positioned the notes in the backdrop of this visual of a connected syllabus shown in Figures $3 a$ and $b$. They wrote KF notes (red notes) and different teachers built on the ideas (lines among icons). In doing so, the teachers redesigned the curriculum using a visual curriculum map (Figure 3a). Students' novelty of ideas and questions, as seen from the notes detailing planned activities, enacted activities, and students' responses, seemed to energize the teachers. Curriculum 
integration also took place in this pre-school community with the teacher teaching the Chinese language and the teacher teaching the English language working together. This was the first time the teachers of the two languages came together to design and coordinate lessons. Before COVID-19 struck, they taught the two languages as distinct subjects based on the respective curriculum, but now they were able to generate big ideas that worked across different subjects using KB principles (see notes in Figure 4).

\section{Importance of Big Ideas (and KB Principles) in KB Practice}

Rather than using disconnected facts, big ideas and idea-driven inquiry are central to realigning the curriculum. Teachers wrote notes in KF on how to use big idea/big questions and $\mathrm{KB}$ principles to improve their lesson activities. As an example, a teacher shared a resource that she had used before, that is, "different sizes and shapes of the bones" in a note on KF. The teachers then used the scaffold supports of $<\mathrm{KB}$ principles $>$ and $<$ Big question/Big ideas $>$ to consider advancing the activity described in the note (Figure 4). Professional development activities are closely coupled with their classroom practice, and teachers see that as being even more important during the COVID-19 period.

\section{Figure 3a}

\section{Curriculum as a Visual Backdrop in a KF View for Teacher Build-on Notes}

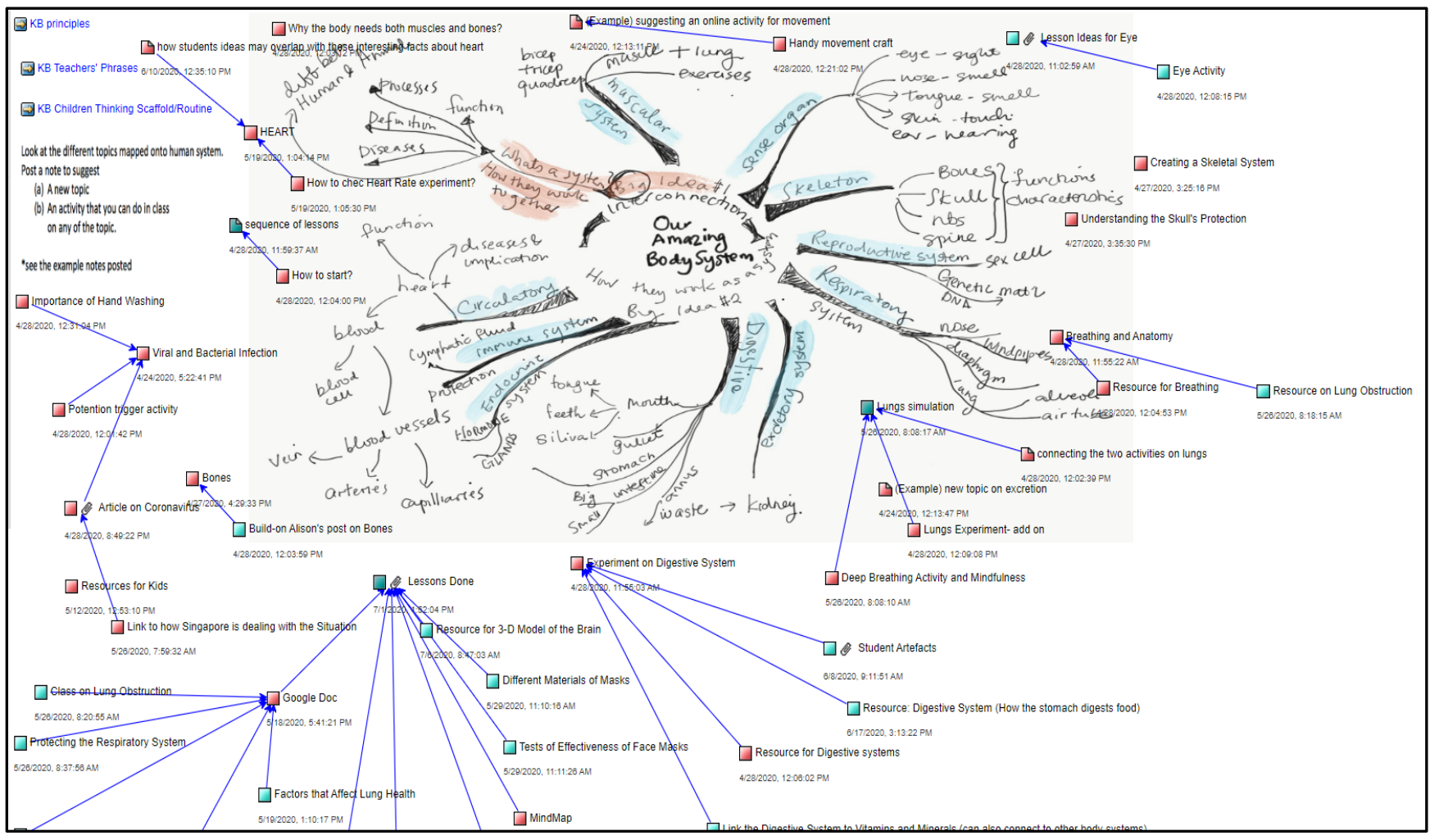




\section{Figure 3b}

KF Note on the Lesson Idea and Lesson Plan with KB Principles

\begin{tabular}{l} 
Bones \\
Read Edit Author(s) Connections History Properties \\
Resource - different sizes and shapes of the bones. - \\
Big question/Big ideas - real and authentic ideas- children can observe the individual bones that comprise a \\
chicken's skeleton and compare them with what they may know about other skeletal systems. Children can examine \\
the dried vertebrae and understand how the bones come together to form the chicken's shape and protect its organs. \\
Big question/Big ideas - Questions: - \\
Why is bone an important organ? \\
How does it helps to protect our other organs? \\
How is our one part of our bone connect to another? \\
\hline
\end{tabular}

The KF notes written by the teachers were often the subject of discussion at each synchronous Zoom meeting. Teachers elaborated on these notes during their meetings. For example, Rina noted that her goal was to get students to relate the activity to their body system "to kind of allow them to relate back to our own body system bones...." Sheeny considered Riana's idea and built on it with a lesson on the digestive system. She explained how she wanted the students to relate the activity to the big topic: "I was thinking how children would be more likely to link the topic into the digestive system itself...." She also reflected on the KB principle of "idea diversity," acknowledging the complexity of the topic: "Children will be able to explore and understand the...idea around that topic...the digestive system is pretty complex...different processes...that's why I use idea diversity."

During the weekly teacher KB sessions, the teachers were encouraged to read and share questions or ideas on KF. The teachers raised more complex pedagogical questions such as sequencing, relevance, and feasibilities of activities relating to the principles. At that point, the teachers started to rationalize those questions from the perspective of children's learning, rather than from their perspective of covering the prescribed syllabus. This pointed back to their efforts in designing the curriculum considering students' ideas. COVID-19 provided opportunities to shift the lens to one that seeks to understand students' ideas. 


\section{Figure 4}

Teacher's Focus on Big Ideas and Principle-based Approach in KF Notes

KF note \#1

"Resource - different sizes and shapes of the bones. -

$<$ real and authentic ideas $>$ children can observe the individual

bones that comprise a chicken's skeleton and compare them

with .....

$<$ Big question/Big ideas $>$ Why is bone an important organ?

How does it help to protect our other organs? How is one part of

our bone connected to another? Is there any reason why our

bones are formed in a particular way?" ("Bone" by Sunny)

KF note \#2

KF note:

"Activity - Creating a digestive system

Resource -

https://www.youtube.com/watch?v=7av19YhNkhE

Big question/Big ideas -

1. Why do we need to eat and drink?

2. How does our food move through our bodies? What body parts do we use to chew our food?

3. Where does food go after we chew it?

4. What do our bodies get from the food we eat?

Have you ever had belly pain? How did you feel? What made you feel better? KB principles - Idea Diversity -" ("Experiment on Digestive System" by Sheeny)

\section{Technology and Knowledge Artefacts}

In this pre-school teacher community, technology was not only used for mimicking face-to-face teaching. There was emerging alignment of pedagogy and technology transformation. As an example, Sheeny creatively harnessed existing technology using Google Docs and an online mind map to connect students' and parents' ideas.

Sheeny shared at the meeting how she used an online mind map to record and capture the young children's rich ideas. The class brainstormed what they knew and what they would like to know about bodies and internal organs. She thought that the introduction of mind maps was the most natural thing to do with the children during HBL in the same way that she saw the connection across the syllabus on the KF. Sheeny attached the link to the mind map on KF and later created a Google Doc for parents and children to post what children did at home. Each week, the KB teacher community saw how the mind map grew in the class. 
The teacher provided a rationale for what it meant for a preschool teacher to connect with fiveyear-olds' ideas in a completely new HBL experience. Technology and pedagogy aligned with the focus of idea-centered curriculum in a KB classroom.

The mind map also served as an object of discourse within the teacher community: "...I saw the Mind Map and I was thinking about the lesson on lungs...so you can share with me how I can do this so I can understand" (Christel). Throughout the online meetings, the community traced how the children's questions and ideas expanded on the online mind map (Figure 5a). As the teacher exited from HBL and returned to class, the mind map that captured the discussion during HBL was converted to a physical poster and brought to class where the students continued to build their ideas around it. There was a smooth transition between the different spaces - physical and HBL.

\section{Figure 5a}

Students' Questions and Ideas Captured on the Online Mind-mapping Tool Linked to the Teacher's Reflection on $K F$

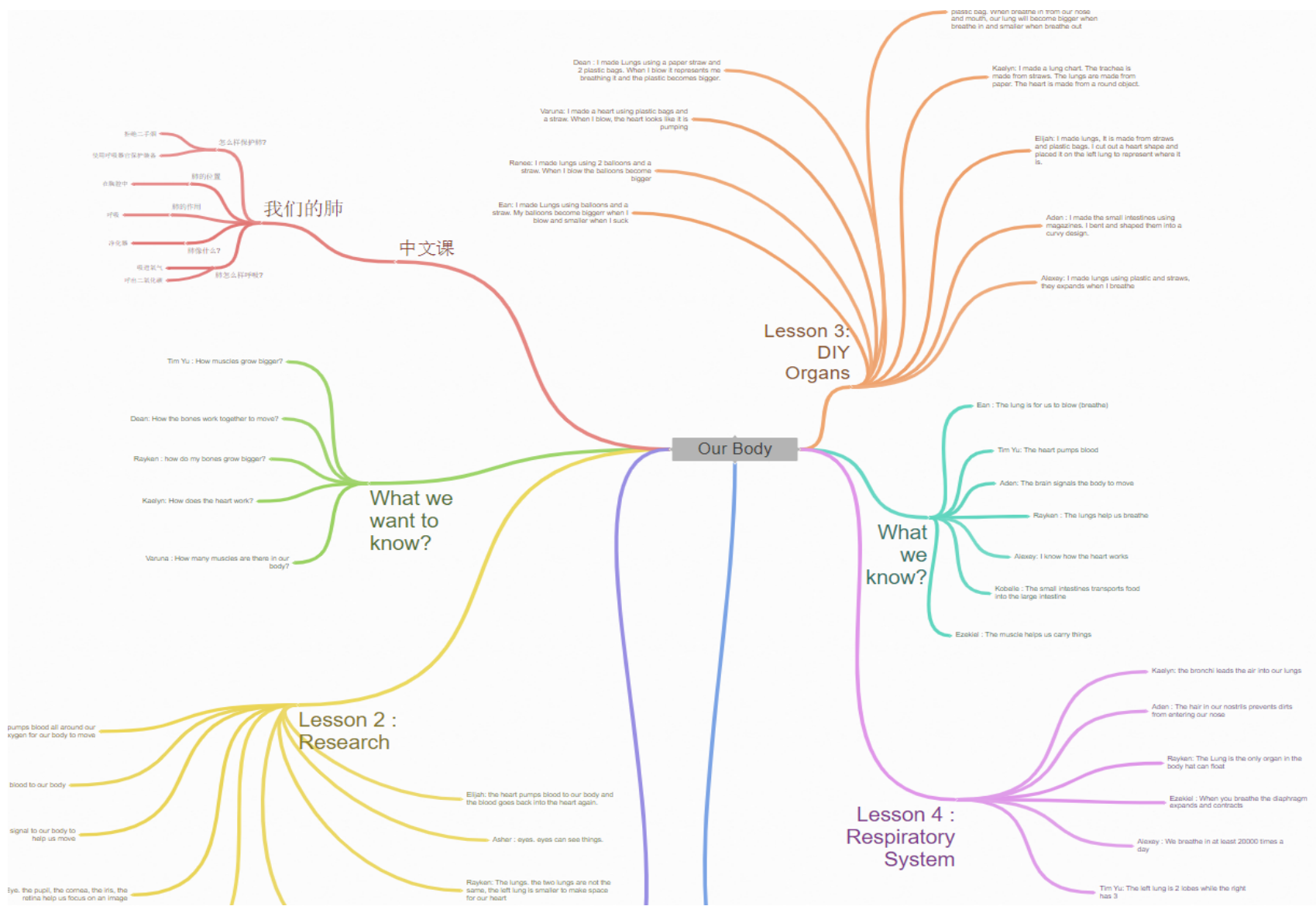




\section{Figure 5b}

Students' Questions and Ideas Captured on the Online Mind Map Converted into a Poster Brought to Class after $H B L$

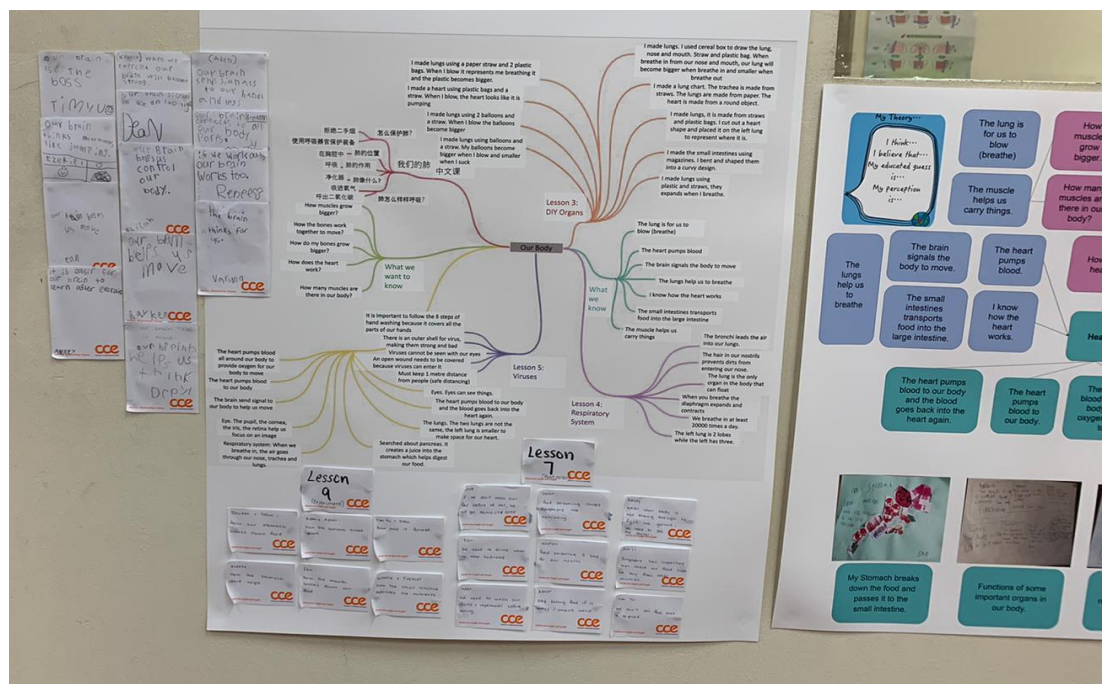

Cathy, a supporting teacher in Sheeny's class, shared how they could use mindmaps to assess children's thinking, "I can see how many kids can read their work," and noted how even young children could use the mind maps. Cathy shared, "So when they see it (the mind map) together, one of the kids was actually asking, 'Why are you not putting this...?' So the child actually (knows) about if we are putting up ideas on what we have said." Technology and pedagogy were aligned - the children took ownership of learning as they saw their questions and ideas grow on the mind map, the Google Doc, and the physical copy of the mind map in class.

As these examples show, technology is used in transformative ways in alignment with ideacentred curriculum and pedagogy. There is an evolving connection of how teachers' PD in KBC is coupled with their classroom practice.

\section{Bringing Parents into the $\mathrm{KBC}$}

During the lockdown, the teacher integrated the online live Google Doc with the mind map to allow parents access to their children's work in class. The teacher community was also accessing live updates of the lesson through these technologies. They explained the connection as a "teaser" to get parents to understand what they were doing. Misalignments between school and HBL were turned into opportunities involving more stakeholders.

These "alignment" efforts from this case-example illustrate the constant arrangement and rearrangement of existing practices and new practices in a cyclical fashion. Each problem of practice was not immediately resolved but induced other processes for further growth. The continual discourse and engagement with ideas in this preschool teacher community had positive effects on these teachers and the larger KBC network. 


\section{Figure 6}

Teacher's KF View with Live Links to Google Doc and Collaborative Mind Map Connecting with Parents and Children's Learning at Home

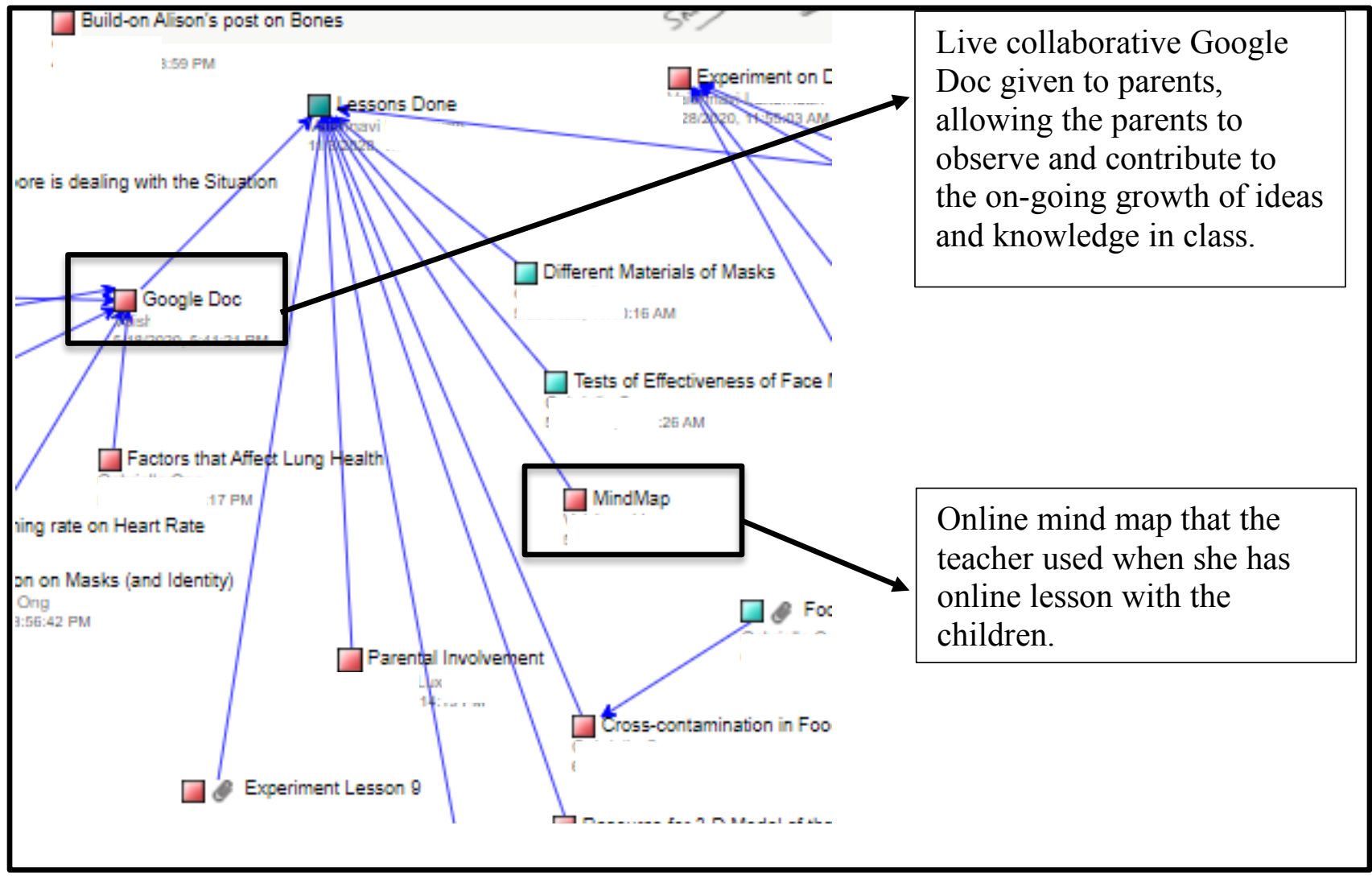

\section{Case Study 3: A Cross-School KBC that Connected the Teachers During HBL}

The teacher KBC consisted of preschools, elementary and secondary schools, and teachers met quarterly for KB professional development. Despite COVID-19, different teachers continued to explore $\mathrm{KB}$ during the lockdown and were connected through the cross-school KBC. Several network Zoom meetings were held in April, May, and September 2020 as they transitioned to face-to-face lessons.

\section{Different Communities Weaving Conversation and Knowledge}

In the first network session, three teachers shared their pedagogical innovation in HBL. Jane shared the beginning stage of her biology class on vertical farming. Sandy and Amy shared their creative design of KF scaffold supports in their upper secondary literature class. Mark, a history teacher, shared his students' virtual posters. In the second session, these teachers reported on their progress and how they adopted the ideas gained in the first session. Sheeny, Yancy (from the preschool in case 2), and Sammy (from another preschool), along with Tom and Andrew (from a Primary school), readily shared their work too.

There was much encouragement and exchange of ideas. Teachers saw the possibility of improving their ideas and advancing collective knowledge on problems and questions on HBL during 
the pandemic. "It was (KBC)...we were able to see how KB can move to a higher level." A first timer in the $\mathrm{KBC}$ commented to his more experienced $\mathrm{KB}$ colleague, "This is such a different community, very refreshing, so many ideas flying around." The teachers' knowledge was transformed through continued participation in the community as they assimilated new ways of thinking and acting. One teacher commented, "We will always think that we cannot do it, but when we see you all do it, it is very motivating."

\section{Teachers as Knowledge Builders and Symmetrical Advances are Made by Expert and Novice Within and Between Communities}

$\mathrm{KBC}$ is designed to empower teachers to collectively design, set progress, and evaluate possibilities. Teachers work like students as knowledge builders inquiring collectively with symmetrical advances. The synergy arising from the collaboration can play a significant part in molding teachers' confidence in their practice. In the following excerpt, we see how one lesson idea was improved upon by the community. Jane spoke about her vertical farming lesson and others built on the lesson (Figure 7).

Jane's pedagogical idea and practice of vertical farming was put forth and progressively advanced with the contribution of the different teachers, making this idea stronger in different contexts. One of the words that frequently appeared in the teacher conversation was "collaborate" and the excerpt with deepening inquiry also provided a glimpse of the KBC culture.

\section{Figure 7}

\section{Teacher Dialogue and Sharing of Ideas at the KBC}

Zoe: $\quad$ "You could even link to authentic setting to stretch further their idea of vertical
farming to include the idea of food security in the Singapore context and global
context... for students who want to pursue this direction."
Andrew: "I am currently doing this topic with my P6 class, maybe we can collaborate on
this."
"Hoe:
see that the teacher is learning too."
Andrew: "How would I facilitate the session if I invite an expert?"
Zoe:
"I think Jane's students were told that they are the host for the forum. Two
students were the host asking the others for questions."

Teachers in the KBC were motivated to engage and there was a sense of trust and connection among teachers. For example, Sheeny shared with her teachers in school immediately after the crossschool KBC meeting, "I got inspired by a primary school teacher during the KB (cross-school KBC) 
meeting to involve the children in a discussion about the essential workers involved in COVID-19...(I am trying this in my class)."

At the various cross-school KBC meetings, Jane reiterated how she saw the need to focus on students' interests and motivation during the HBL period. Jane shared her future directions for the next few weeks to move the students' promising ideas into a new KF view for students to share and improve upon. The other teachers encouraged Jane to continue her focus on students. There was progressive growth and symmetrical advances among different communities as teachers worked together supported by the KBC.

\section{Teachers Creating Knowledge in Practice Supported by Technology}

Teachers connected their design meeting experiences with their classroom practice using KF technology during the COVID-19 lockdown. In this teacher $\mathrm{KBC}$, teachers wrote on $\mathrm{KF}$ inquiring into the KB principles connecting with their practice, and different members built on those practices to improve the ideas. Figure 8 shows teachers building on others' practice. A teacher posted a note on "summary of design" describing the KB activities on fish tanks that were planned. The other teachers suggested possible modification to expand the concepts that students could explore in the design. For example, in the 'sustainability of fish tank' note, the teacher suggested including plants in the tank to generate more ideas on sustainability.

Sammy encapsulated the spirit of KB in this statement, "I don't know as a team, whether we understand everything... as a person, as an individual I am still learning, and as a team also when we discuss with each other, we will say, 'Eh, I think we could have done this.' We are trying to everyday improvise and improve." In the KBC, teachers were involved in creating improvable practice.

\section{Discussion: Emerging Alignments for Transformative Pedagogy and Teacher Learning}

This paper examines a KBC through three connected case studies on how the KBC has been sustained throughout the pandemic. We analyzed the teachers' interactions through asynchronous discourse and synchronous conferencing and their implementation of HBL and physical lessons. Table 1 summarizes the key themes of the KBC processes addressing the major areas of misalignments during the pandemic. Emerging alignments for transformative pedagogy and teacher learning, turning disruptions into opportunities for innovative KB practice, are discussed. 


\section{Figure 8}

Discussion Threads and Notes in a Cross-School Teacher's KF View

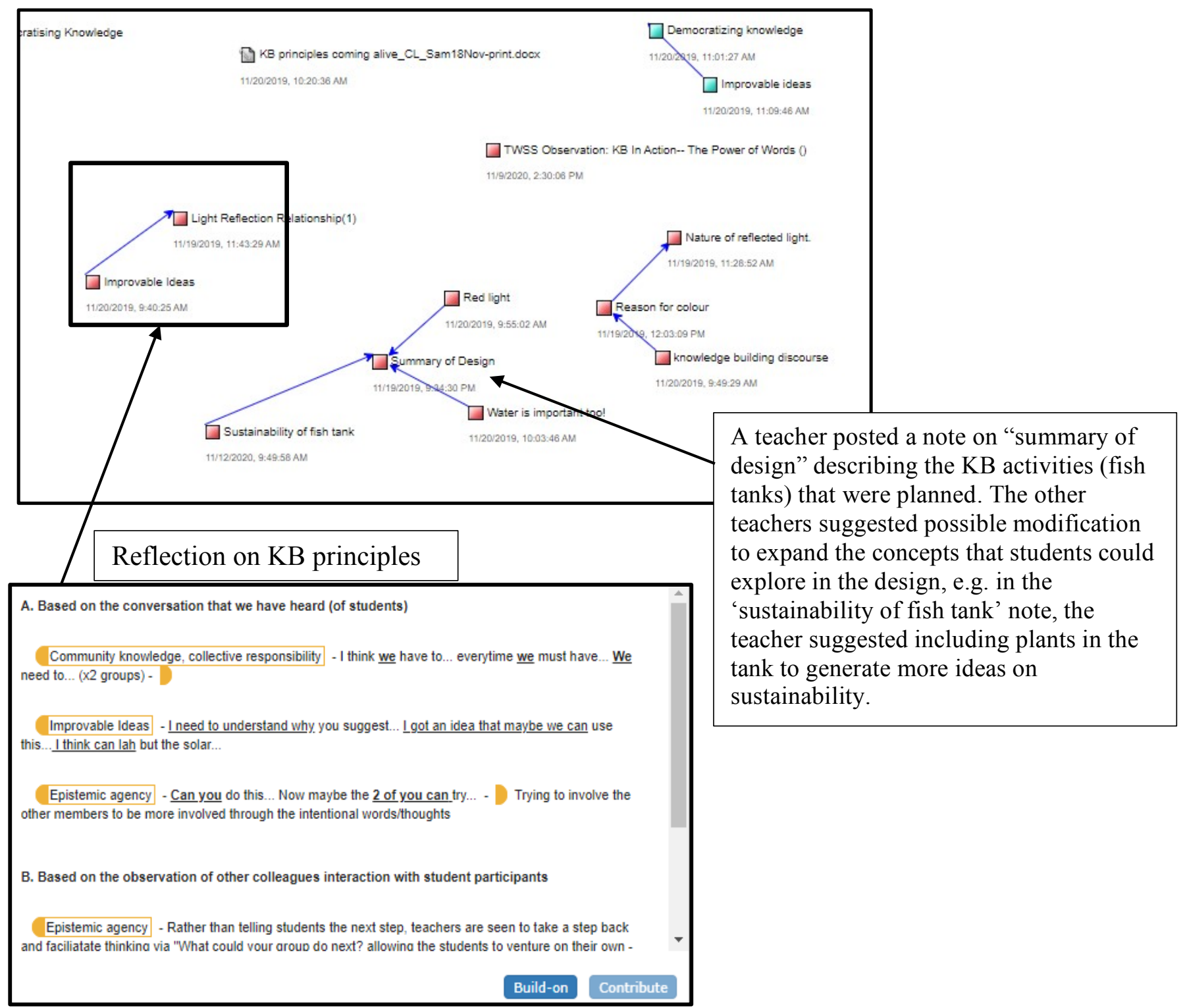

Centrality of Ideas and Principles: Developing Coherence Within a Subject, Across Subjects, as well as In and Out of Schools

A major misalignment during the COVID-19 lockdown was the disjoint in learning, including the separation within and across a subject, as well as between school-based learning and HBL. In this paper, realignment includes connecting ideas within a class and connecting learning in and out of school. The COVID-19 disruptions have prompted the teachers to pursue coherence and community support by focusing on realigning the curriculum and working with students' ideas in and out of class. In the preschool teacher community example, KB teachers demonstrated their collective effort to develop and elaborate on an idea-centric curriculum in the face of the challenge of HBL. With 
fragmentation and disjointure due to HBL, they focused on thinking about big ideas and KB principles in student activities. The teachers were inspired to steer the students to see the connections between big ideas instead of learning isolated facts.

\section{Table 1}

Misalignments and Teachers' Navigation of the Problem Spaces for Emerging Realignments

Misalignments $\quad \begin{aligned} & \text { Emerging alignments from KBC for transformative pedagogy } \\ & \text { and teacher learning }\end{aligned}$

Disjointure in learning, both within a Centrality of ideas and principles

subject, across subjects, and between learning in and out of

Realigning curriculum: calibrating syllabus and developing ideaclassrooms. centric curriculum

Focusing on the centrality of real-world ideas and problems Idea-focused pedagogy: Importance of big ideas and principles for student agency

Designing connected curriculum and pedagogy across different subjects

Pervasive KB

Seamless moves between home and school; online and offline; $\mathrm{KB}$ anywhere and everywhere

Using technologies to imitate physical teaching.
Transformative use of technology

Flexible use of technology and knowledge artefacts connecting teaching and learning

Using technology in productive ways and enculturation into an idea-centric technology design

Technology-based knowledge artifacts to mediate interaction between teachers, students and parents, and experts
The disconnect between teachers' professional development and practice.

Teachers' professional development does not align with the classroom practice that was aspired to.
Symmetrical advancement within and across KB communities

Classroom practice aligned with teachers' professional development experience in KBC

Weaving of conversation and community discourse supported by technology for knowledge advancement

Distribution of agentic leadership in communities

A cross-school KBC that connects experienced and novice teachers, researchers, different communities working together

The pandemic also provided opportunities for teachers to question their earlier practice. Applying the idea-centric principle, teachers calibrated their syllabus against the students' ideas and questions, rather than merely following a pre-conceived sequence of teaching. The KB culture of engaging in continual and collective idea improvement to tackle emerging problems, despite the 
challenge of the pandemic, helped teachers to persevere in supporting students' deep learning through innovative approaches.

The disruption also inspired other changes resulting from the teachers' concerns with the inadequacies of videos as teaching tools during HBL. The introduction of the real problem on vertical farming in the lessons on photosynthesis for Teacher Jane indicated a willingness to give students the choice and voice to construct knowledge in their own way; trusting that the collaborative process of learning would be more effective than the delivery of information via videos. The collaborative process empowered students to share the responsibility of charting their learning trajectory. Each student could engage in more meaningful and relevant learning activities that would not have been possible if everyone was made to do the same thing. By doing so, the teacher linked the school syllabus with authentic problems, thus connecting learning in and out of classrooms. Bringing in experts to the online discussions further supported pervasive learning.

\section{Transformative Use of Technology: Flexible Use of Technology and Knowledge Artefacts Connecting Teaching and Learning}

Another misalignment was how technology was used and perceived by teachers during the COVID-19 pandemic. The crisis compelled educators to conduct online lessons, for which they were unprepared, revealing their deep-seated beliefs as well as their predominant approaches in designing online lessons. Their attempts to replicate a face-to-face mode of teaching and learning into an online mode might fall short in leveraging the affordances of technologies to transform teaching and learning. Teachers had to be supported to find new practices using technology that they valued or which was valuable in teaching and learning.

The KBC revealed how teachers appreciated the constant changes that went on in their children's minds and treated it as their daily digest. During the pandemic, the teachers leveraged different technologies embedded with idea-centric pedagogy; for example, online mind maps and collaborative Google Doc to complement KF. They printed those online knowledge artefacts and brought them back to the physical classrooms to capture students' ideas and give students a chance to see their ideas grow, and in a way, ensure the continuity of ideas in and out of the classroom. The evidence showed that the teachers approached technology in the way they were enculturated into an idea-centric technology design. Consequently, affordances of technologies were appropriately leveraged to transform pedagogy for online learning rather than to force-fit traditional pedagogy with new technologies.

\section{Symmetrical Advancement and Systemic Processes in Teacher KB Community Connecting Professional Development and Practice}

Contrary to the common disconnect between teachers' professional development and practice, the teachers approached their classroom practice in ways that were aligned with their PD experience in the $\mathrm{KBC}$. With the support of the teacher $\mathrm{KBC}$, there was richness and creativity in the ways the teachers implemented HBL during the lockdown and how they advanced together. As the teachers reflected, individually and collectively, on how they embed KB principles and big ideas in the 
curriculum and pedagogy, we observed a more confident approach to KB in their classes. The teachers' reflections on the ways the $\mathrm{KBC}$ has supported their work was valuable, suggesting a positive shift towards the collective. The preschool teacher Sheeny summed it up in her reflection:

So I'm taking all the knowledge that I'm gaining through the meetings, through the conversations, and all the different Knowledge Forum notes... then we just merge ideas together, and it becomes an even better idea.

The KBC systemic process has worked well to support teachers in their classroom practice through the pandemic. First, the knowledge of KB practice that drove their teaching actions was within the teachers' experience in and out of their classroom. Through the KBC's weekly meetings, including those held during the pandemics, the teachers constantly differentiated and verified the KB theories, pedagogy, and technology while they collaborated to apply and prioritize this knowledge in their practices. Bridging the gap between what they learned and what they had to practice in a sustained and concurrent manner, the teachers worked as knowledge builders as they created their KB practice. This is in contrast to a more traditional workshop setting where teachers are left to try the pedagogy on their own after the workshop.

Second, there was alignment between theory and practice, unlike most training and teacher PD in many educational settings. The professional discourse the teachers received mirrored the way they engaged the students. Simply put, the professional learning discourse and activities of the teachers in the KBC were directly aligned with what they were supposed to be doing in schools. The cross-school $\mathrm{KBC}$ created multiple points of connections for a robust exchange of ideas. As the teachers shared their practice in the cross-school KBC with those from other schools working with children of different backgrounds, their sense of ownership of the practice and community grew.

\section{Conclusion}

The tyranny of the COVID-19 crisis has compelled schools worldwide to replace face-to-face teaching with online learning overnight. The misalignments in the teaching and learning approaches, involving disjoint in home-school learning, piecemeal use of technology, and disconnected teacher practice and professional development are highlighted. We propose the use of a coherent knowledgebuilding community model with its inherent focus on a systemic approach and cyclical processes to tackle different areas of misalignments within a multi-level and multi-sector system. Rather than replacing technology or mimicking face-to-face learning, there is continual realignment and transformation happening in the KBC. The cases and narratives of the teacher KBC look at how teachers navigate these misalignments illuminating their developing capacities. Their perspectives and experiences reveal the emerging alignments required to sustain innovative pedagogy and technology through the community approach for bringing us beyond COVID-19 to the new normal.

$\mathrm{KB}$ innovation and practice, in these cases, is challenging but worthwhile. KB principles and practices discussed in $\mathrm{KBC}$ meetings were translated into classroom practice. In particular, the ideacentric principles guided the teachers to help students connect ideas in a class, across subjects, and in 
and out of the classrooms. The teachers in different communities served as agents to weave the conversation and knowledge from different layers of teacher KBC into practical knowledge. This systemic community approach is grounded in the KB principle of symmetrical advancement that transcends both within and across school communities, supported by the distribution of members who take up the responsibility to play a different leadership role, the defining characteristic of the KBC. The "less structured" design approach and open discourse platform thrived during the lockdown and became the draw to teachers and schools in tackling HBL with potential for a new normal. With the need to deal with unforeseen circumstances, teachers were more active in sharing and building new practices in KBC. Consequently, the interactions among different members are no longer hierarchical, rather, they are replaced by a network of people, ideas and resources, enriching the capacity for making collective advances.

This paper illustrates how the vision and practice of a teacher $\mathrm{KBC}$ can bring about emerging realignments for innovative practice, turning crisis into opportunity. Engaging in a $\mathrm{KBC}$ can develop a disposition in teachers to embrace novel situations in their daily work. With the propensity to continuous innovation emphasized in a $\mathrm{KBC}$, teachers displayed a positive mindset towards "uncertainties," which could be critical to teachers' sustained innovation in using disruptions to spark changes. 


\section{References}

Bereiter, C., \& Scardamalia, M. (2014). Knowledge building and knowledge creation: One concept, two hills to climb. In S. C. Tan, H. J. So, \& J. Yeo (Eds.), Knowledge creation in education (pp. 35-52). Springer. https://doi.org/10.1007/978-981-287-047-6 3

Bolam, R., McMahon, A., Stoll, L., Thomas, S., Wallace, M., Greenwood, A., Hawkey, K., Ingram, M., Atkinson, A., \& Smith, M. (2005). Creating and sustaining effective professional learning communities. (Research report RR637). University of Bristol.

https://dera.ioe.ac.uk/5622/1/RR637.pdf

Chan, C. K., \& Yang, Y. (2018). Developing scientific inquiry in technology-enhanced learning environments. In R.L. Raby \& E.J. Valeau (Eds.), Handbook of comparative studies on community colleges and global counterparts (pp. 1-20). Springer.

Chan, C. K., \& Van Aalst, J. (2008). Collaborative inquiry and knowledge building in networked multimedia environments. In Voogt J., Knezek G. (Eds) In International handbook of information technology in primary and secondary education (pp. 299-316). Springer. https://doi.org/10.1007/978-0-387-73315-9 18

Chan, C. K., Lai, K-W., Bielaczyc, K.,Tan, S.C., Ma, L., Scardamalia, M., Bereiter, C., Friesen, S., Massey,L., McAuley, S., Millwood, R., Philip, D., \& Reeve, R. (2020). Knowledge building/knowledge creation in the classroom, school, and beyond. In P. Fisser \& M. Phillips (Eds.), Learners and learning contexts: New alignments for the digital age (pp.101-110). International Summit on ICT in Education. https://www.edusummit2019.fse.ulaval.ca/files/edusummit2019 ebook.pdf

DuFour, R., DuFour, R., Eaker, R., \& Many, T. (2016). Learning by doing: A handbookfor professional learning communities at work ( $3^{\text {rd }}$ ed.). Solution Tree Press.

Ebert-May, D., Derting, T. L., Hodder, J., Momsen, J. L., Long, T. M., \& Jardeleza, S. E. (2011). What we say is not what we do: Effective evaluation of faculty professional development programs. BioScience, 61(7), 550-558. https://doi.org/10.1525/bio.2011.61.7.9

Ferdig, R. E., Baumgartner, E., Hartshorne, R., Kaplan-Rakowski, R., \& Mouza, C. (Eds). (2020). Teaching, technology, and teacher education during the CoVID-19 pandemic: Stories from the field. Association for the Advancement of Computing in Education (AACE). https://www.learntechlib.org/p/216903/

Hayes, D., Mills, M., Christie, P., \& Lingard, B. (2020). Teachers and schooling making a difference: Productive pedagogies, assessment and performance. Routledge. https://doi.org/10.4324/9781003117643 
Larson, J. S., \& Archambault, L. (2019). The Extent of K-12 Online Teacher Development. In Handbook of Research on Emerging Practices and Methods for K-12 Online and Blended Learning, 55-77. https://doi.org/10.4018/978-1-5225-8009-6.ch003

Laferrière, T. (2018). Boundary crossings resulting in active learning in preservice teacher education: A CHAT analysis revealing the tensions and springboards between partners. Frontiers in ICT, 5. https://doi.org/10.3389/fict.2018.00022

McLaughlin, M. W., \& Talbert, J. E. (2006). Developing Communities of Practice in Schools. Building school-based teacher learning communities : professional strategies to improve student achievement / Milbrey W. McLaughlin, Joan E. Talbert. (pp. 38-63). Teachers College Press.

Nahal, S. P. (2010). Voices from the field: Perspectives of first-year teachers on the disconnect between teacher preparation programs and the realities of the classroom. Research in Higher Education Journal, 8, 1-19.

Scardamalia, M. (2002). Collective cognitive responsibility for the advancement of knowledge. Liberal Education in a Knowledge Society, 97, 67-98.

Scardamalia, M., \& Bereiter, C. (2010). A brief history of knowledge building. Canadian Journal of Learning and Technology, 36(1), https://doi.org/10.21432/T2859M

Tan, S. C., Chan, C. K., Bielaczyc, K., Ma, L., Scardamalia, M., \& Bereiter, C. (2021). Knowledge building: Aligning education with needs for knowledge creation in the digital age. Education Technology Research and Development. https://doi.org/10.1007/s11423-020-09914-X

Toh, Y., Jamaludin, A., Hung, W. L. D., \& Chua, P. M. H. (2014). Ecological leadership: Going beyond system leadership for diffusing school-based innovations in the crucible of change for 21st century learning. The Asia-Pacific Education Researcher, 23(4), 835-850. https://doi.org/10.1007/s40299-014-0211-4

Yang, Y., van Aalst, J., \& Chan, C. K. (2020). Dynamics of reflective assessment and knowledge building for academically low-achieving students. American Educational Research Journal, 57(3), 1241-1289. https://doi.org/10.3102/0002831219872444

UNESCO Report. (2020). New UNESCO Report shows extent of global inequalities in education and calls for greater inclusion as schools re-open. https://en.unesco.org/news/GEM-Report-2020 


\section{Authors}

Chew Lee, Teo is a Senior Research Scientist at the Center of Research in Pedagogy and Practice, National Institute of Education, Singapore. She is currently the Programme Director of Learning Sciences \& Innovation and has been working on Knowledge Building pedagogy and technology since her earlier days as a school teacher. Chewlee.teo@nie.edu.sg

Seng Chee, Tan is an Associate Professor with the Learning Sciences and Assessment academic group, National Institute of Education, Singapore. He is also the Associate Dean, Graduate Education by Research. His research interests include integration of technologies in education, ComputerSupported Collaborative Learning, knowledge building, and adult learning. Sengchee.tan@nie.edu.sg

Carol Chan is the Honorary Professor and Research Leader at the Human Communication, Development, and Information Sciences in Hong Kong University. Her area of expertise includes Knowledge Building; Learning Sciences; Computer-Supported Collaborative Learning; Cognition, Learning and Instruction. ckkchan@,hkucc.hku.hk

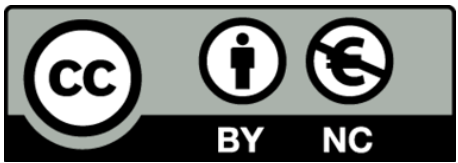

This work is licensed under a Creative Commons Attribution-NonCommercial CC-BY-NC 4.0 International license. 